\title{
HISTOPATOLOGIA DE FÍGADO, RIM E BAÇO DE Piaractus mesopotamicus, Prochilodus lineatus E Pseudoplatystoma fasciatum PARASITADOS POR MYXOSPORÍDIOS, CAPTURADOS NO RIO AQUIDAUANA, MATO GROSSO DO SUL, BRASIL*
}

\author{
CRISTIANE M. DE CAMPOS ${ }^{1}$; JULIETA R. E. DE MORAES²; E FLÁVIO R. DE MORAES ${ }^{2}$
}

\begin{abstract}
CAMPOS, C.M.; MORAES, J.R.E.; MORAES, F.R. [Histopathology of liver, kidney and spleen of Piaractus mesopotamicus, Prochilodus lineatus and Pseudoplatystoma fasciatum infected by myxosporean parasite, caugth in Aquidauana River, Mato Grosso do Sul, Brazil]. Histopatologia de fígado, rim e baço de Piaractus mesopotamicus, Prochilodus lineatus e Pseudoplatystoma fasciatum parasitados por myxosporídios, capturados no rio Aquidauna, Mato Grosso do Sul, Brasil. Revista Brasileira de Parasitologia Veterinária, v. 17, n. 4, p. 200-205, 2008. Unidade Universitária de Aquidauana,Universidade Estadual de Mato Grosso do Sul, Rod. Aquidauana-Cera, km12, Zona Rural, Aquidauana, 79200-000, MS, Brasil. Email:cmeldau@uems.br

Histological analysis of kidney, spleen and liver of Piaractus mesopotamicus, Prochilodus lineatus and Pseudoplatystoma fasciatum, infected by myxosporean, caugth in Aquidauana river, MS, was studied. After necropsy, samples of liver, previous kidney and spleen were fixed in $10 \%$ buffered formalin and processed followed histological routine methods. Sections of $5 \mu \mathrm{m}$ were stained with hematoxylin and eosin. Myxobolus porofilus, M. colossomatis and were found in P. lineatus, in P. mesopotamicus respectively and Myxobolus spp. Were also found in all three species of fish. Myxosporideans cysts in the liver and spleen of P. mesopotamicus were also related. Up to $50 \%$ of $P$. mesopotamicus and $P$. lineatus liver samples showed diffuse hepatodistrofy. Liver sections also showed concentric hialin structures in over $80 \%$ of samples and esteatosis in $50 \%$ of them. In P. mesopotamicus kidney, $95.23 \%$ of them showed tissue changes consisted of $60 \%$ with diffuse moderate nefrodistrofy and congestion of glomerular sinusoids. In P. lineatus kidney, $20 \%$ of the samples showed tissues changes. No heavy damage was observed in the fish spleen.
\end{abstract}

KEY WORDS: Histological alterations, natural environment, parasites, fishes.

\section{RESUMO}

Este estudo descreveu a histopatologia de rim, baço e fígado de Piaractus mesopotamicus, Prochilodus lineatus e Pseudoplatystoma fasciatum, parasitados por mixosporídios, capturados no Rio Aquidauana, MS. Após necropsia, amostras do fígado, rim cefálico e baço foram colhidas, fixadas em formalina a $10 \%$ tamponada e processadas de acordo com a rotina histológica. Os cortes foram feitos à espessura de $5 \mu \mathrm{m}$

\footnotetext{
*Sob os auspícios da CAPES

${ }^{1}$ Unidade Universitária de Aquidauana, Universidade Estadual de Mato Grosso do Sul, Rod. Aquidauana-CERA, km 12, Zona Rural, Aquidauana, MS 79200-000, Brasil. E-mail: cmeldau@uems.br

${ }^{2}$ Centro de Aqüicultura da UNESP, Universidade Estadual Paulista Júlio de Mesquita Filho, Campus de Jaboticabal, Via de Acesso Prof. Paulo Donato Castellane s/n, Jaboticabal, SP 14884-900, Brasil.
}

e corados com hematoxilina-eosina. Foram encontrados Myxobolus porofilus em $P$. lineatus, $M$. colossomatis em $P$. mesopotamicus e Myxobolus spp. nas três espécies de hospedeiros. Cistos de mixosporídios no exame histopatológico foram vistos no fígado e baço de $P$. mesopotamicus. Mais de $50 \%$ das amostras de fígado de P. mesopotamicus e $P$. lineatus apresentou hepatodistrofia difusa. Mais de $80 \%$ das amostras de fígado de $P$. fasciatum apresentou formações hialinas concêntricas e esteatose em 50\% das amostras. Em 95,23\% das amostras de rins de $P$. mesopotamicus, foram observadas alterações teciduais, e em mais de $60 \%$ dos casos nefrodistrofia difusa moderada e congestão de sinusóides glomerulares. Alterações teciduais nas amostras de rins de $P$. lineatus foram observadas em menos de $20 \%$ da amostra. No baço dos peixes ora examinados não foram encontradas lesões dignas de relato. 
PALAVRAS-CHAVE: Alterações histológicas, ambiente natural, parasitos, peixes.

\section{INTRODUÇÃO}

Nos teleósteos a hematopoiese ocorre principalmente no estroma do baço e no interstício dos rins e, em menor extensão, nas áreas peri-portais do fígado, submucosa do intestino e timo (AGIUS; ROBERTS, 2003), uma vez que os peixes são desprovidos de medula óssea e de linfonodos (TAVARESDIAS; MORAES, 2004). Entretanto, há variações, podendo determinada espécie ter um ou mais órgãos com tecidos mielóides e linfóides associados.

Os teleósteos apresentam quantidade variável de centros melanomacrófagos ou agregados de macrófagos nos diferentes tecidos, em particular fígado, baço e rim (MESSEGUER et al., 1994). Os centros melanomacrófagos são comumente nodulares com delicada cápsula argirofílica e geralmente restrito aos canais vasculares (AGIUS, 1985).

São inúmeras as funções atribuídas aos melanomacrófagos, tais como: fagocitose de patógenos resistentes como esporos de parasitos e bactérias (ROBERTS, 1975); processamento de antígenos na resposta imune (AGIUS, 1985); destruição, detoxificação ou reciclagem de materiais endógenos e exógenos (FERGUSON, 1976; ELLIS, 1980, HERRAEZ; ZAPATA, 1986); depósito de metabólitos de células mortas, incluindo-se os eritrócitos (ROBERTS, 1975; AGIUS, 1980; FULOP; MCMILLAN, 1984) e resposta a corpos estranhos, incluindo agentes infecciosos (AGIUS; ROBERTS, 2003).

Os centros melanomacrófagos estão associados à presença intracelular de bactérias ácido-resistentes como as micobactérias e parasitos como Myxobolus spp. (ROBERTS, 2001). Há evidências de que melanomacrófagos desempenham papel relevante no controle de infecções por mixosporídios (SUPAMATTAYA et al., 1993).

Rins parasitados por disporoblastos e esporos do mixosporídio Polysporoplasma sparis (PALENZUELA et al., 1999) já foram observados.

Todavia a literatura sobre esse assunto é escassa, fato esse que motivou a presente investigação com o objetivo de registrar informações sobre histopatologia do rim, baço e fígado de Piaractus mesopotamicus, Prochilodus lineatus e Pseudoplatystoma fasciatum, parasitados por mixosporídios.

\section{MATERIAL E MÉTODOS}

Para este estudo foram realizadas coletas durante o período de março de 2003 a novembro de 2004 no rio Aquidauana,

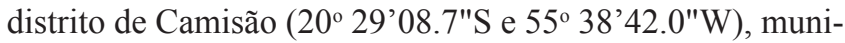
cípio de Aquidauna, MS. Um total de 62 peixes foi capturado com rede de espera e lance, cujas malhas variaram de seis a $17 \mathrm{~cm}$ entre nós opostos e tarrafas de três a $12 \mathrm{~cm}$ entre nós.

Foram analisados 33 espécimes de pacus $P$. mesopotamicus, 19 de curimbatás $P$. lineatus e 10 cacharas $P$. fasciatum. Espécimes de P. mesopotamicus tinham comprimento padrão entre 34 e $55 \mathrm{~cm}$ e peso total entre $1.425 \mathrm{e}$
$4.970 \mathrm{~g}$, sendo nove fêmeas e 22 machos. Dos 19 exemplares de $P$. lineatus coletados, nove eram fêmeas, nove machos e um indivíduo não teve o sexo identificado. $\mathrm{O}$ comprimento padrão variou entre 23 e $40 \mathrm{~cm}$ e o peso total entre $300 \mathrm{e}$ $1.980 \mathrm{~g}$. Foram amostrados cinco fêmeas e cinco machos de P. fasciatum, entre os meses de setembro e outubro de 2004, com comprimento padrão médio de $70,25 \mathrm{~cm}$ e peso total médio de 4.770,5 g.

Os animais foram anestesiados com benzocaína até o óbito, pesados (g), medidos (cm), necropsiados e seus órgãos coletados para exame parasitológico a fresco e histológico. Os órgãos amostrados foram macerados entre lâmina e lamínula para verificar presença de esporos e/ou cistos de mixosporídios. Amostras do fígado, rim cefálico e baço foram coletadas e fixadas em formalina $10 \%$ tamponada. Após a fixação, foram desidratadas, diafanizadas e incluídas em parafina. Os cortes foram feitos à espessura de $5 \mu \mathrm{m}$, corados com HE e observados sob microscópio de luz.

\section{RESULTADOS}

Neste estudo foram encontrados Myxobolus porofilus em $P$. lineatus, Myxobolus colossomatis em P. mesopotamicus e Myxobolus spp. nas três espécies de hospedeiros.

O exame histopatológico de fígado de P. mesopotamicus e de $P$. lineatus revelou que $100 \%$ das amostras apresentaram algum tipo de alteração morfológica. Para essas duas espécies, mais de $50 \%$ das amostras apresentou hepatodistrofia difusa caracterizada principalmente por vacuolização, congestão e hemossiderose de leve a moderada. Em P. mesopotamicus havia figuras hialinizadas semelhantes a estruturas de nematóides em cortes transversal ou oblíquo, esteatose (Figura 1), infiltrado inflamatório peri-portal crônico, em diversos graus, composto por células mononucleares e fibroblastos, necrose focal de magnitude variável em que os núcleos estavam ausentes, com picnose e/ou cariólise e as membranas celulares descontínuas. Foram observados vários centros de melanomacrófagos, de diferentes tamanhos, que continham

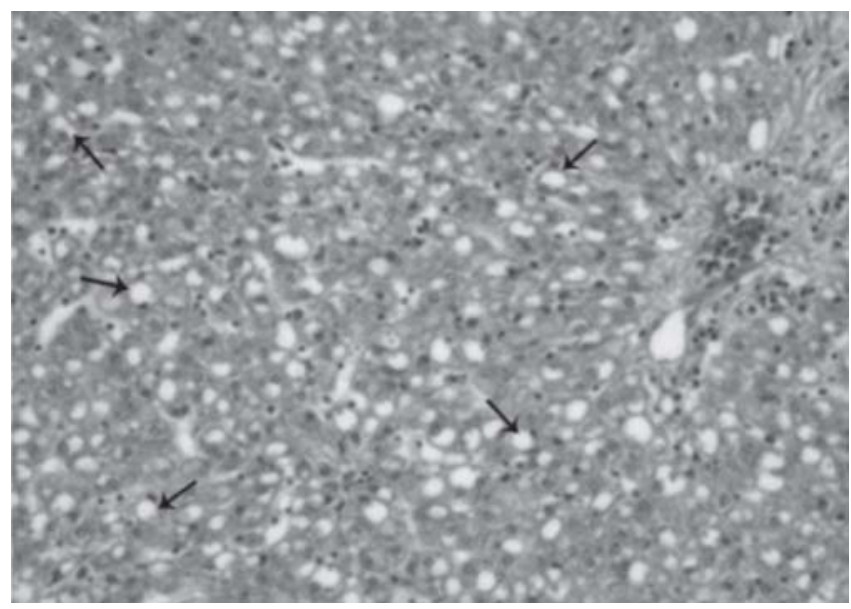

Figura 1. Esteatose (seta) nos hepatócitos de Piaractus mesopotamicus. 400X. HE 
pigmentos como melanina, hemossiderina e ceróides no interior de uma cápsula delicada. Estavam presentes alguns cistos semelhantes aos de mixosporídios aderido à cápsula hepática constituídos por uma delgada membrana eosinofílica envolvendo estruturas alongadas basofílicas mais intensamente coradas em um dos pólos, lembrando cápsula polar, e o restante mais claro ou pálido sugerindo estrutura flagelar.

A histopatologia de fragmentos de fígado de P. fasciatum apresentou formações hialinas concêntricas cortadas transversalmente que se assemelhavam a nematoda em mais de $80 \%$ das amostras. Essas estruturas estavam isoladas do restante do tecido hepático por duas a três camadas de fibroblastos. Havia esteatose em $50 \%$ delas, além de granulomas, congestão, centros melanomacrófagos, infiltrado mononuclear discreto próximo ao sistema porta. Os granulomas apresentavam o centro necrótico com espessa fibroplasia formando cápsula com macrófagos e linfócitos infiltrados.

Nas amostras de rim de P. mesopotamicus, 95,23\% apresentou alterações teciduais, e foi observado em mais de $60 \%$

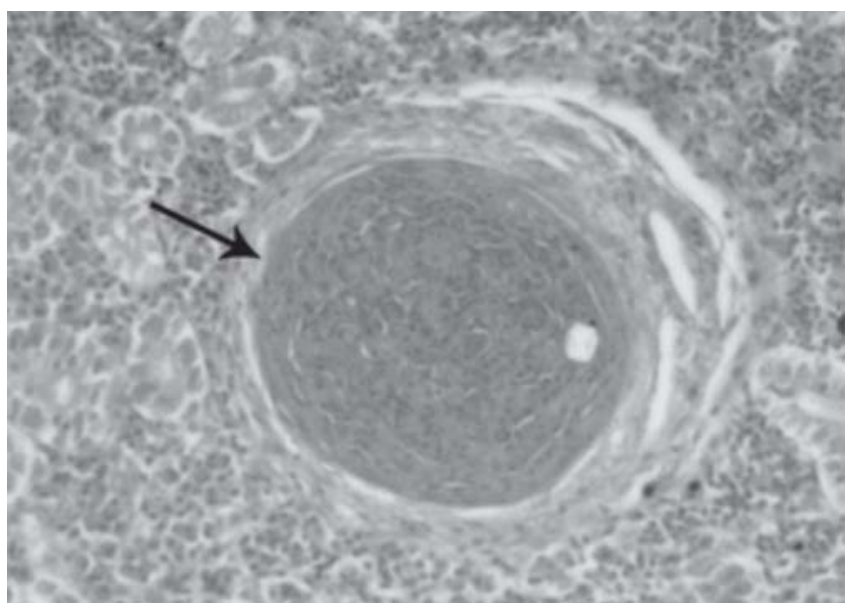

Figura 2. Inflamação crônica granulomatosa (seta) sugestiva de micobacteriose na camada cortical do rim de Piaractus mesopotamicus. 400X. HE.

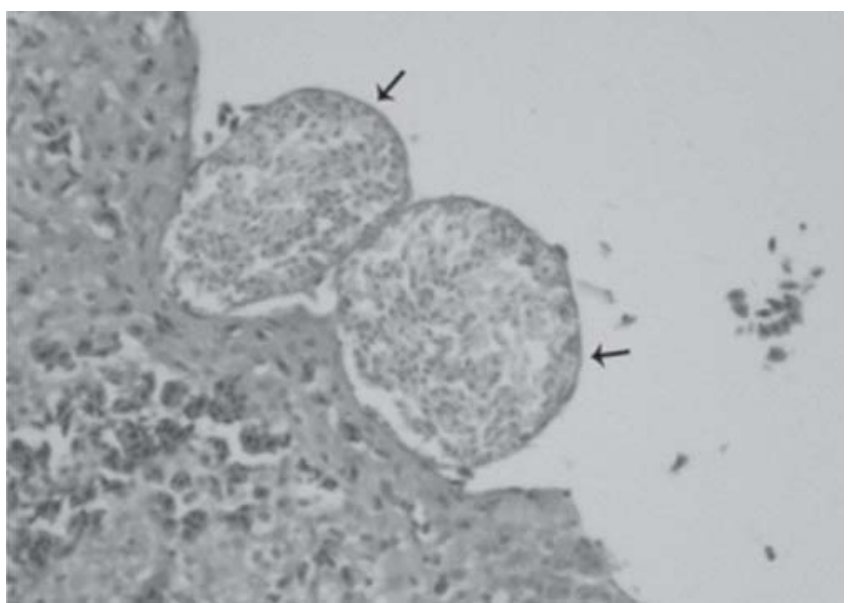

Figura 3. Baço de Piaractus mesopotamicus com cistos de mixosporídios (setas) contendo esporos, fixados à cápsula esplênica. 400X. HE. dos casos nefrodistrofia difusa moderada e congestão de sinusóides glomerulares e, em mais de $40 \%$ dos casos, hialinização tubular discreta. Em menor proporção observouse edema intersticial discreto, focos hemorrágicos, nefrose discreta, glomeruloesclerose e cistos semelhantes aos de mixosporídios. Observou-se a presença de granulomas com alto grau de fibroplasia, necrose na região central circundada por tecido conectivo, macrófagos e linfócitos (Figura 2).

Embora $100 \%$ das amostras de rins de P. lineatus tivessem alguma alteração, com exceção da enorme quantidade dos centros melanomacrófagos e congestão, as outras alterações teciduais foram observadas em menos de $20 \%$ da amostra. Observou-se nefrodistrofia caracterizada por vacuolização citoplasmática difusa moderada, necrose focal discreta, infiltrado inflamatório intertubular, hemorragia e formações hialinas concêntricas e em camadas, sugerindo cortes transversais de nematoda, como os observados no fígado.

A histologia do baço de $P$. mesopotamicus evidenciou polpa vermelha em 37,5 \% associada à congestão. Havia figuras hialinizadas concêntricas semelhantes às observadas no fígado e no rim, presença de centros melanomacrófagos e cistos de mixosporídios (Figura 3).

$\mathrm{O}$ baço de $P$. lineatus apresentou centros melanomacrófagos, congestão e um cisto calcificado, sendo que em $P$. fasciatum foram evidenciados centros melanomacrófagos, congestão e formações hialinas concêntricas.

\section{DISCUSSÃO}

Neste trabalho, várias das lesões observadas conhecidas como hepatodistrofias, por exemplo, a hipertrofia de hepatócitos, congestão, esteatose e necroses estão relacionadas aos processos de intoxicação sendo a extensão e gravidade da lesão proporcional ao tipo, duração, severidade da agressão e estado fisiológico da célula envolvida (ROBBINS; COTRAN, 2005). O fígado dos peixes é especialmente susceptível à ação de produtos químicos graças à lentidão do fluxo sangüíneo em relação ao débito cardíaco. Além disso, o fluxo biliar é cerca de 50 vezes mais lento que o de mamíferos, tornando mais vagarosa a depuração de produtos tóxicos (GINGERICH, 1982). Então os elementos tóxicos que chegam ao fígado pela corrente sangüínea exercerão seus efeitos nos hepatócitos por maior tempo do que o fariam em mamíferos. Talvez também seja válido afirmar que em peixes as substâncias tóxicas possam causar transtornos hepáticos em concentrações mais baixas do que as necessárias para mamíferos. Assim é sugestivo que as lesões ora encontradas sejam resultantes da contaminação ambiental por pesticidas de uso agrícola, entre outros, visto que o rio Aquidauana atravessa extensas áreas de exploração agropecuária.

Os peixes atuam como hospedeiro intermediário ou paratênico de muitas espécies de ascarídeos como, por exemplo, o gênero Contracaecum spp., que, dependendo da espécie, tem como hospedeiro primário vários crustáceos copépodes e como definitivo os peixes, aves ou mamíferos 
aquáticos. Assim a migração errática de larvas de nematoda por vísceras como o fígado não é incomum embora migrem por outras localizações anatômicas do hospedeiro (ROBERTS, 2001). No caso ora observado não foi possível diagnosticar os possíveis agentes causadores dos processos inflamatórios. Todavia essas estruturas não estavam causando danos ao hospedeiro uma vez que já se encontravam encapsuladas e isoladas, com pouca reação tecidual.

Rodrigues et al. (2002) ao examinar fígado de dourado Salminus maxillosus do rio Mogi-Guaçu, Estado de São Paulo, observaram cistos esbranquiçados de Neocucullanus neocucullanus no parênquima hepático, circunscritos à região da instalação do parasito. Havia intensa desorganização do tecido e inflamação. Todavia, neste estudo, como no exame parasitológico esse parasito não foi observado, então, essa possibilidade foi descartada.

No Brasil, mixosporídios do gênero Myxobolus sp. foram observados por Molnár e Békési (1993) em tambaquis do Rio Amazonas, M. colossomatis por Martins et al. (1999) em pacus, tambaquis e tambacus, criados na região nordeste do Estado de São Paulo e Myxobolus braziliensis por Casal et al. (1996) em Bunocephalus coracoideus (Siluriforme da Amazônia). Neste estudo, os exames parasitológicos revelaram a presença de Myxobolus porofilus em P. lineatus, $M$. colossomatis em P. mesopotamicus e Myxobolus spp. nas três espécies de hospedeiros. Assim, os cistos observados no exame histopatológico podem pertencer a qualquer dos mixosporídios acima referidos, visto que no fígado também havia cistos semelhantes aos de mixosporídios. Esses parasitos estão habitualmente presentes nos peixes silvestres e de cativeiro, sem causar qualquer tipo de problema quando a relação entre o hospedeiro e o ambiente está equilibrada (LOM; NOBLE, 1984) como é o caso dos peixes ora examinados.

Centros de melanomacrófagos foram observados no fígado e no tecido hematopoiético do rim e baço dos peixes ora examinados, como descrito na literatura (ROBERTS, 2001). Essas estruturas têm analogia primitiva com os centros germinativos de linfonodos das aves e mamíferos (FERGUSON, 1976; ELLIS, 1980) e contêm diferentes pigmentos, como a melanina, hemossiderina, lipofucsina, pigmento lipogênico que podem auxiliar nos mecanismos de defesa do hospedeiro (AGIUS; AGBEDE, 1984; ROBERTS, 1989). A presença de melanina ou lipofucsina livre, oriunda da ruptura dos centros melanomacrófagos, é observada na infecção por Aeromonas hydrophila (ROBERTS, 1989). A melanina pode absorver ou neutralizar radicais livres (AGIUS; AGBEDE, 1984), cátions e outros agentes tóxicos, derivados da degradação de material celular fagocitado (ZUASTI et al., 1998), tem importância na produção de compostos bactericidas especialmente peróxido de hidrogênio (WOLKE et al., 1985). Peixes como os agora examinados, em ambiente natural, sujeitos ao ataque de agentes biológicos e químicos, apresentaram diferentes graus e tipos de lesões sugerindo a possibilidade dessas agressões. Como reação o organismo pode estimular repostas de centros melanomacrófagos, justificando sua presença e número no fígado.
Nas amostras de rins de P. mesopotamicus, 95,23\% tiveram alterações teciduais, havendo em mais de $60 \%$ dos casos nefrodistrofia difusa moderada, constituída por processos degenerativos vacuolares nas células epiteliais dos túbulos renais e congestão de sinusóides glomerulares e, em mais de $40 \%$ dos casos, hialinização tubular discreta. Em menor proporção observaram-se pequenos focos hemorrágicos e nefrose discreta. Em rim de P. lineatus as alterações foram basicamente as mesmas, apenas menos severas.

A nefrodistrofia vacuolar pode ser resultado do efeito de metais pesados como o mercúrio (TRUMP et al., 1975) ou da ação de produtos bactericidas como a eritromicina e sulfamerazina (HICKS; GERACI, 1984). A lesão pelo mercúrio ocorre nos túbulos proximais embora não se tem notícia do uso de agentes anti-microbianos na área em que os peixes foram coletados. Os ambientes naturais estão contaminados com diversos poluentes, entre eles o mercúrio, em função da mineração, desgaste de depósitos minerais, sistemas aquáticos e terrestres contaminados, emissões vulcânicas e principalmente a queima de florestas (NRIAGU, 1994; CAMARGO. 2002), esta última freqüente na região em que os peixes foram colhidos.

A inflamação crônica granulomatosa observada no tecido renal pode ser causada por diferentes agentes e é de certo modo comum. Os granulomas são descritos na infecção por flavobactérias (KLLUGE, 1965), na micobacteriose em Pleuronectes platessa (TIMUR; ROBERTS,1977); na infecção por Edwardisiella tarda (MIYAZAKI; KAIGE, 1985); no parasitismo por Pseudoterranova decipiens em trutas Oncorhynchus mykiss e Gadus morhua (RAMAKRISHNA; BURT, 1991); por Mycrosporidium sp. na musculatura esquelética de Trisopterus esmarkii (PULSFORD; MATHEUS, 1991); por Ichthyophonus hoferi em Pleuronecte platessa (TIMUR;TIMUR, 1984), pela injeção de carragenina em P. platessa (TIMUR et al., 1977), pelo implante de tecido ósseo desmineralizado de Anguilla anguilla em tecido muscular de Scyliorhinus canicula (PEINGNOUDEVILLE et al., 1989) e pela inoculação de BCG em Oreochromis niloticus (MATUSHIMA, 1994). Os peixes são continuamente expostos às micobactérias, mas o desenvolvimento clínico da doença torna-se secundário a problemas como superpopulação, desnutrição, baixa qualidade da água, idade, entre outros (HARMS et al., 2003) e da ação de predadores. Os granulomas, ora encontrados, caracterizam-se por intensa reação fibroblástica formando uma cápsula espessa, tendo de permeio, nas regiões mais externas, macrófagos e linfócitos. As descrições da literatura acima citada, de modo geral, mencionam ainda a presença de eosinófilos. O diagnóstico apenas morfológico, é insuficiente para caracterizar o agente causador havendo necessidade do uso de outros métodos mais específicos que, em geral, não são utilizados rotineiramente.

No baço dos peixes ora examinados não foram encontradas lesões que mereçam maior atenção. Todavia, Eiras e Rego (1987) analisando histologicamente o baço de Paratrygon sp. 
encontraram larvas do nematóide Eustrongylides sp. alojadas no parênquima. $\mathrm{O}$ tecido reacional constituiu uma cápsula homogênea em toda a sua extensão, composta de fibroblastos e fibras colágenas. Os autores também observaram macrófagos situados entre a cápsula e o exterior do órgão, zona onde observaram um acentuado grau de necrose. Neste estudo não foram identificadas larvas do referido parasito.

Os achados encontrados e confrontados com a literatura demonstram que os peixes de ambientes naturais, embora sadios, podem ter a saúde comprometida particularmente por poluentes e parasitos. No caso dos parasitos o problema é de certo modo autolimitante uma vez que o efeito de predador colabora para o controle das parasitoses. Todavia, a contaminação por poluentes, em particular os metais pesados, é muito mais séria, pois a intoxicação é cumulativa e coloca em risco a saúde pública diante do consumo desses peixes.

Agradecimentos: Os autores agradecem a Maria Inês Yamazaki de Campos e Francisca de Assis Ardisson, auxiliares técnicas do Laboratório de Diagnóstico em Patologia do Departamento de Patologia Veterinária da UNESP, Campus de Jaboticabal e ao Dr. Edson A. Adriano do CEPTA/ IBAMA pelo auxílio na identificação das espécies de mixosporídios.

\section{REFERÊNCIAS BIBLIOGRÁFICAS}

AGIUS, C. Phylogenetic development of melano-macrophage centers in fish. Journal of Zoology, v. 191, n. 1, p.11-31, 1980.

AGIUS, C. The melano-macrophage centers in fish: a review. In: MANNING, M.J.; TATNER, M.F. (Eds.). Fish Immunology. London: Academic Press, 1985, p.85-105.

AGIUS, C.; AGBEDE, S.A. An electron microscopical study on the genesis of lipofucsin melanin and hemosiderin in the hemopoietic tissues of fish. Journal of Fish Biology, v. 34, n. 4, p. 471-488, 1984.

AGIUS, C.; ROBERTS, R.J. Melano-macrophage centers and their role in fish pathology. Journal of Fish Disease, v. 26, n. 9, p. 499-509, 2003.

CAMARGO, J.A. Contribution of Spanish-American silver mines (1570-1820) to present high mercury concentrations in the global environment: a review. Chemosphere, v. 48, n. 1, p. 51-57, 2002.

CASAL, G.; MATOS, E.; AZEVEDO, C. Ultrastructural data on the life cycle stages of Myxobolus braziliensis n. sp., parasite of an Amazonian fish. European Journal of Protistology, v. 32, n. 1, p. 123-127, 1996.

EIRAS, J.C.; REGO, A.A. Histopatologia da parasitose de peixes do rio Cuiabá (Mato Grosso) por larvas de Eustrongylides sp. (Nematoda, Dioctophymidae). Revista Brasileira de Biologia, v. 48, n. 2, p. 273-280, 1987.

ELLIS, A.E. Antigen-trapping in the spleen and kidney of the plaice Pleuronectes platessa L. Journal of Fish Disease. v. 3, n. 5, p. 413-426, 1980.

FERGUSON, H.W. The relationship between ellipsoids and melano-macrophage centers in the spleen of turbot
(Scophthalmus maximus). Journal of Comparative Pathology, v. 86, n. 3, p. 377-380, 1976.

FULOP, G.M.I.; McMILLAN, D. Phagocytosis in the spleen of the sunfish Lepomis spp. Journal of Morphology, v. 179, n. 2, p. 175-195, 1984.

GINGERICH, W.H. Hepatic toxicology of fishes. In: WEBER, L.F. (ed.) Aquatic toxicology, New York: Plenum Press. 1982. p. 55-105.

HARMS, C.A.; HOWARD, K.E.; WOLF, J.C.; SMITH, S.A.; KENNEDY-STOSKOPF, S. Transforming growth factorâ response to mycobacterial infection in striped bass Morone saxatilis and hybrid tilapia Oreochromis spp. Veterinary Immunology and Immunophathology, v. 95, n. 3-4, p. 155163, 2003.

HERRAEZ, M.P.; ZAPATA, A.G. Structure and function of the melano-macrophage centers of the goldfish Carassius auratus. Veterinary Immunology and Immunopathology. v. 12, n. 1-4, p. 117-126, 1986.

HICKS, B.D.; GERACI, J.R. A histological assessment of damage in rainbow-trout, Salmo gairdneri Richardson, fed rations containing erythromycin. Journal of Fish Disease, v. 7, n. 6, p. 457-465, 1984.

KLLUGE, J.P. A granulomatous disease of fish produced by flavobacateria. Veterinary Pathology, v. 2, p. 545-552, 1965.

LOM, J.; NOBLE, E.R. Revised classification of the class Myxosporea Bütschli, 1981. Folia Parasitologica, v. 31, n. 3, p. 193-205, 1984.

MARTINS, M.L.; SOUZA, V.N.; MORAES, J.R.E.; MORAES, F.R.; COSTA, A.J. Comparative evaluation of the susceptibility of cultivated fishes to the natural infection with myxosporean parasites ant tissue changes in the host. Revista Brasileira de Biologia, v. 59, n. 3, p. 263-269, 1999.

MATUSHIMA, E.R. Avaliação do processo inflamatório crônico granulomatoso induzido experimentalmente através da inoculação de BCG em peixes da espécie Oreochromis niloticus - tilápia do Nilo. 1994. 110f. (Tese de Doutorado) - Faculdade de Medicina Veterinária e Zootecnia da Universidade de São Paulo, São Paulo, 1994.

MESSEGUER, J.; LOPEZ-RUIZ, A.; ESTEBAN, M.A. Melano-macrophages of the seawater teleosts, sea bass (Dicentarchus labrax) and gilthead seabream (Sparus aurata): morphology, formation and possible function. Cell Tissue Research, v. 277, n. 1, p. 1-10, 1994.

MIYAZAKI, C.F.; KAIGE, N. Comparative histopahology of edwadsiellosis in fishes. Fish Pathology, v. 20, n. 2-3, p. 219-227, 1985.

MOLNÁR, K.; BÉKÉSI, L. Description of a new Myxobolus species, M. colossomatis n. sp. from the teleost Colosoma macropomum of the Amazon River basin. Journal of Applied Ichthyology, v. 9, n. 1, p. 57-63, 1993.

NRIAGU, J.O. Mechanistic steps in the photoreduction of mercury in natural waters. Science of the Total Environment. v. 154, n. 1, p. 1-8, 1994.

PALENZUELA, O.; ÁLVAREZ-PELLITERO, P.; SITJÀBOBADILLA, A. Glomerular disease associated with 
Polysporoplasma sparis (Myxozoa) infections in cultured gilthead sea bream, Sparus aurata L. (Pisces: Teleostei). Parasitology, v. 118, n. 3, p. 245-256, 1999.

PEINGNOUX-DEVILLE, J.; BORDAT, C.; VIDAL, B. Demonstration of bone resoubing cells in elasmobranchs comparison with osteoclasts. Tissue and Cell, v. 21, n. 6, p. 925-933, 1989.

PULSFORD, A.; MATTHEUS, R.A. Macrophages and giant cells associated with a microsporidian parasite causing liquefaction of the skeletal muscle of the Norway pout Trisopterus esmarkii. Journal of Fish Disease, v. 4, n. 1, p. 67-78, 1991.

RAMAKRISHNA, N.R.; BURT, M.D. Tissue response of fish by larval Pseudoterranova decipiens (Nematoda; Ascaridoidea). Canadian Journal of Fisheries and Aquatic Sciences, v. 48, n. 9, p. 1623-1628, 1991.

ROBBINS, S.; COTRAN, R.S. Patologia - Bases Patológicas das Doenças. In: KUMAR, V.; ABBAS, A.K.; FAUSTO, N. (Eds) Elsevier: Rio de Janeiro. 2005. 1592p.

ROBERTS, R.J. Melanin-containing cells of the teleost fish and their relation to disease. In: RIBELIN, W. E.; MIGAKI, G. (Ed.) The Pathology of Fishes. Madison: University of Wisconsin Press, 1975. p. 339-428.

ROBERTS, R.J. The pathophysiology and systematic pathology of teleosts. In: ROBERTS, R.J. (Ed.) Fish pathology. 2nd ed. London: Baillière Tindall, 1989. p. 56-134.

ROBERTS, R.J. Fish Pathology. 3rd ed, London: W.B. Saunders 2001. 472p.

RODRIGUES, E.L.R.; RANZANI-PAIVA, M.J.T.; SANTOS, A.A. Alterações histopatológicas em fígado de dourado Salminus maxillosus Valenciennes, 1840 (Osteichthyes, Characidae) causadas por Neocucullanus neocucullanus Travassos, Artigas \& Pereira 1828 (Nematoda). Acta Scientiarum, v. 24, n. 2, p. 455-459, 2002.
SUPAMATTAYA, K.; FISCHER-SCHERL, T.; HOFFMANN, R.W.; BOONYARATPALIN, S. Light and electron microscopic observations on presporogenic and sporogenic stages of Sphaerospora epinepheli (Myxosporea) in grouper (Epinephellus malabaricus). Journal of Eukaryotic Microbiology, v. 40, n. 1, p. 71-80, 1993.

TAVARES-DIAS, M.; MORAES, F.R. Hematologia de peixes teleósteos. Ribeirão Preto: M. Tavares-Dias. 2004. $144 \mathrm{p}$.

TIMUR, G.; ROBERTS, R.J.; McQUEEN, A. A carragenin granuloma in the plaice (Pleuronectes platessa): a histopathological study of chronic inflammation in a teleost fish. Journal of Comparative Pathology, v. 30, n. 1, p. 8996, 1977.

TIMUR, G.; ROBERTS, R.J. The experimental pathogenesis of focal tuberculosis in the plaice (Peuronectes platessa). Journal of Comparative Pathology, v. 87, n. 1, p. 83-87, 1977.

TIMUR, G.; TIMUR, M. Giant cell reaction associated with Ichthyophonus hoferi in wild plaice, Pleuronectes platessa. Journal of Fish Disease, v. 7, n. 6, p. 513-514, 1984.

TRUMP, B.F.; JONES, R.T.; SAHAPHONG, S. Cellular effects of mercury on fish kidney tubules. In: RIBELIN, W.E.; MIGAKI, G. (Ed.). The Pathology of Fishes. Madison: University of Wisconsin Press, 1975. p. 585-612.

WOLKE, E.R.; MURCHELANO, R.A.; DICKSTEIN, C.D.; GEORGE, C.J. Preliminary evaluation of the use of macrophage aggregates (MA) as fish health monitors. Bulletin of Environmental Contamination and Toxicology, v. 35, n. 1, p. 222-227, 1985.

ZUASTI, A.; JIMENEZ-CERVANTES, C.; GARCIABORON, J.C; SERRER, C. The melanogenic system of Xenopus laevis. Archives für Histologie and Cytologie, v. 61, n. 4, p. 305-316, 1998.

Recebido em 10 de maio de 2007.

Aceito para publicação em 30 de dezembro de 2008. 